\title{
Mehanokemijska sinteza kalcijeva oksalata
}

\section{Sažetak}

Ova studija prikazuje mehanokemijsku sintezu kalcijeva oksalata u planetarnom kugličnom mlinu, bez prisutnosti i uz prisutnost otapala. Dosadašnja istraživanja uglavnom su bila usmjerena na otopinsku sintezu kalcijeva oksalata. U ovom radu opisujemo drugačiji pristup, koji će donijeti nova saznanja o sintezi kristala kalcijeva oksalata, koje su uzrokovane utjecajem mehaničke energije.

Cilj istraživanja je sinteza, identifikacija i karakterizacija pojedine oksalatne hidratne faze sintetizirane iz kalcijevih soli (klorida, nitrata i sulfata). Ispitivan je utjecaj brzine mljevenja i praćena je reakcija u ovisnosti o vremenu sinteze. Strukturalna i termička svojstva uzoraka ispitana su spektroskopijom FTIR i termogravimetrijskom analizom (TGA). Morfološke karakteristike kalcijeva oksalata te raspodjela veličine čestica određene su optičkom mikroskopijom i dinamičkim raspršenjem svjetlosti (DLS).

\section{Ključne riječi}

Mehanokemija, kalcijev oksalat monohidrat, bubrežni kamenci

\section{Uvod}

Prijelom Urolitijaza se danas smatra jednim od najčešćih poremećaja urinarnog trakta. Prema posljednjim epidemiološkim podacima, učestalost pojave bubrežnih kamenaca neprestano raste posebice $u$ industrijaliziranim zemljama kao rezultat modernog i ubrzanog načina života, ali i neadekvatne prehrane. Stvaranje bubrežnih kamenaca ovisi o kemijskom sastavu urina, komponentama koje mogu promovirati i/ili inhibirati proces, vrijednosti $\mathrm{pH}$, ionskoj jakosti te prezasićenosti. ${ }^{1}$

U sastavu bubrežnih kamenaca mogu se pronaći različite soli fosfata i kalcija, međutim u najvećem se udjelu pojavljuju kalcijevi oksalati. Kalcijevi oksalati kristaliziraju u tri hidratna oblika: termodinamički stabilan kalcijev oksalat monohidrat $\left(\mathrm{CaC}_{2} \mathrm{O}_{4} \cdot \mathrm{H}_{2} \mathrm{O}, \mathrm{COM}\right)^{2,3}$ metastabilan kalcijev oksalat dihidrat $\left(\mathrm{CaC}_{2} \mathrm{O}_{4} \cdot 2 \mathrm{H}_{2} \mathrm{O}, \mathrm{COD}\right)^{4,5}$ te metastabilan kalcijev oksalat trihidrat $\left(\mathrm{CaC}_{2} \mathrm{O}_{4} \cdot 3 \mathrm{H}_{2} \mathrm{O}\right.$, COT). ${ }^{6,7} \mathrm{COM}$ i COD najčešće se pronalaze u sastavu bubrežnih kamenaca, dok je COT rijetko prisutan. Studije o kalcijevim oksalatima najveći naglasak stavljaju upravo na proučavanje COM zbog njegove patogenosti. ${ }^{8}$ Istraživanja na kalcijevim oksalatima uglavnom su usmjerena na sinteze u otopini. ${ }^{9-11}$
Mehanokemijska sinteza je vrsta sinteze u čvrstom stanju (solid-state) kojom se u sustav dovodi mehanička energija, koja kao pokretačka sila kemijske reakcije uzrokuje povećan kontakt između čestica, pobuđivanje lokalnih reakcijskih mjesta te povećanje specifične površine tvari uslijed uspostavljanja visokoenergetskog stanja. Jedna od velikih prednosti te metode jest mogućnost sinteze $u$ odsutnosti otapala (ili uz dodatak vrlo male količine), što je istodobno čini brzom, ekološki prihvatljivom i vrlo korisnom za pojedine reakcije uz izbjegavanje pojave solvatacijskih učinaka. Mehanokemijski su procesi iznimno korisni za dobivanje čestica od nekoliko nanometara do nekoliko mikrometara. Osim same veličine čestica, također se može dobiti i uniformnija raspodjela njihovih veličina. ${ }^{12,13}$

Cilj ovog istraživanja je sinteza najstabilnije hidratne faze kalcijeva oksalata, COM, mehanokemijskom sintezom iz kalcijevih soli bez dodatka i s dodatkom male količine vode. Tako sintetiziran COM u budućnosti može biti prikladan kao model in vitro za proučavanje rasta kristala i učinka potencijalnih inhibitora/aktivatora na stvaranje bubrežnih kamenaca.

\footnotetext{
*Autor za dopisivanje: dr. sc. Anamarija Stanković, prof. biologije

i kemije, e-pošta: aster@kemija.unios.hr
} 


\section{Eksperimentalni dio}

\subsection{Materijali}

Za mehanokemijsku sintezu kalcijeva oksalata upotrijebljene su tri vrste kalcijevih soli: klorid $\left(\mathrm{CaCl}_{2} \cdot 2 \mathrm{H}_{2} \mathrm{O}\right.$, BDH Prolabo), sulfat $\left(\mathrm{CaSO}_{4} \cdot 2 \mathrm{H}_{2} \mathrm{O}\right.$, Kemika) i nitrat $\left(\mathrm{Ca}\left(\mathrm{NO}_{3}\right)_{2} \cdot 4 \mathrm{H}_{2} \mathrm{O}\right.$, T.T.T.) te natrijev oksalat $\left(\mathrm{Na}_{2} \mathrm{C}_{2} \mathrm{O}_{4}\right.$, $\mathrm{BDH}$ Prolabo). Navedene kemikalije su p.a. Čistoće. Deionizirana voda (provodnosti $\leq 0,055 \mu \mathrm{S} \mathrm{cm}^{-1}$ ) rabljena je u sintezama u kojima je dodavana minimalna količina otapala te pri ispiranju uzoraka. Sinteze su provedene mljevenjem i usitnjavanjem polaznih reaktanata $u$ planetarnom kugličnom mlinu Fritsch Pulverisette 7 (volumen reakcijske posude, $V=20 \mathrm{~cm}^{3}$, promjer posude, $D_{\mathrm{v}}=4,5 \mathrm{~cm}$, promjer rotirajućeg diska, $\left.R_{\mathrm{p}}=140 \mathrm{~mm}\right) \mathrm{s}$ kuglicama od nehrđajućeg čelika ( $n=80$, promjer, $d_{\mathrm{b}}=5 \mathrm{~mm}$; gustoća, $\rho=7,7 \mathrm{~g} \mathrm{~cm}^{-3}$ i masa, $m=0,51 \mathrm{~g}$ ). Prisutnost zaostalih aniona nakon reakcije ispitan je kvalitativnom analitičkom metodom za dokazivanja aniona.

Otopina srebrova nitrata $\left(c\left(\mathrm{AgNO}_{3}\right)=0,1 \mathrm{~mol} \mathrm{dm}^{-3}\right)$ upotrijebljena je za dokazivanje kloridnih iona, otopina barijeva nitrata $\left(c\left(\mathrm{Ba}\left(\mathrm{NO}_{3}\right)_{2}\right)=0,1 \mathrm{~mol} \mathrm{dm}^{-3}\right) \quad$ za dokazivanje sulfatnih iona te $1 \%$-tna otopina difenilamina za dokazivanje nitratnih iona.

\subsection{Karakterizacija sintetiziranih uzoraka}

Za karakterizaciju taloga kalcijeva oksalata primijenjene su sljedeće metode: spektroskopija FTIR, termogravimetrijska analiza (TG), metoda DLS za određivanje prosječne veličine i disperzije čestica te svjetlosna mikroskopija.

IR spektri snimljeni su pomoću spektrometra Shimadzu FTIR $8400 S$ u valnom području od 400 do $4000 \mathrm{~cm}^{-1}$ (rezolucija: $4 \mathrm{~cm}^{-1}$ ) tehnikom DRS. Analizirani su spojevi u čvrstom stanju, a za snimanje je primijenjena tehnika DRIFT (eng. Diffuse Reflectance Infrared Fourier Transform). Približno 1 mg krutog uzoraka pomiješan je s $100 \mathrm{mg} \mathrm{KBr}$. Za snimanje spektara i obradu podataka primijenjen je računalni program IR Solution 1.30.

Analiza TG provedena je na instrumentu Mettler Toledo System 1. Uzorci su ispitivani u atmosferi kisika, uz brzinu protoka plina $200 \mathrm{~cm}^{3} \mathrm{~min}^{-1}$, s korakom snimanja $5{ }^{\circ} \mathrm{C}$ min $^{-1}$ u temperaturnom području od 30 do $300{ }^{\circ} \mathrm{C}$. Rezultati su obrađeni pomoću računalnog programa STARe Software 10.0.

Za vizualnu identifikaciju taloga i za utvrđivanje morfoloških karakteristika istaloženih faza, upotrijebljen je svjetlosni mikroskop (Motic, B1) opremljen digitalnom kamerom (Moticam 2). Prosječna veličina i disperzija čestica određena je dinamičkim raspršenjem svjetlosti (DLS) pomoću uređaja Zetasizer Nano ZS, Malvern, opremljenog zelenim laserom $(532 \mathrm{~nm})$. Intenzitet raspršenog svjetla detektiran je pod kutom od $173^{\circ}$. Rezultati su prikazani kao maksimumi pikova raspodjele veličine čestica po volumenu. Sva su mjerenja ponovljena šest puta. Mjerenja su provedena na $25^{\circ} \mathrm{C}$.

\subsection{Mehanokemijska sinteza kalcijeva oksalata}

Sinteze su provedene u planetarnom kugličnom mlinu (slika 1) dodatkom polaznih reaktanata u masenom omjeru $1: 1$. U svim serijama sinteza, omjer mase reaktanata $i$ mase kuglica bio je konstantan (1:8), dok su mijenjani polazni reaktanti (kalcijeve soli) te brzina $(250,500 \mathrm{i}$ 750 o min $^{-1}$ ) i vrijeme (1 i 2 h) mljevenja. Mehanokemijski procesi usporedno su provedeni bez otapala (samo s krutinama reaktanata) i uz malu količinu otapala $(V($ vode $)=5 \mathrm{ml})$. Analize uzoraka napravljene su prije i nakon ispiranja. Uzorci iz svih serija sinteza isprani su minimalnom količinom deionizirane vode.

\section{Rezultati i rasprava}

\subsection{Karakterizacija kalcijevih oksalata}

Mehanokemijskom sintezom kalcijeva oksalata dobiven je najstabilniji hidratni oblik kalcijev oksalat monohidrat, COM u svim uzorcima s dodatkom i bez dodatka vode. Prisutnost COM ispitan je spektroskopijom FTIR usporedbom dobivenih rezultata s literaturnim podatcima standarda COM (tablica 1). Termogravimetrijskom analizom omogućena je kvantitativna analiza. Teoretski gubitak mase za kristalnu vodu u čistom COM je $12,33 \% .{ }^{14-16}$ Termogravimetrijska analiza u svim sustavima provedena je na ispranim i osušenim uzorcima nakon $2 \mathrm{~h}$ sinteze. Rezultati termogravimetrijske analize uzoraka (tablice 2, 3 i 4) ukazuju na to da se gubitak mase dogodio tijekom samo jednog koraka.

$$
\mathrm{COM}-\mathrm{CaC}_{2} \mathrm{O}_{4} \cdot 1 \mathrm{H}_{2} \mathrm{O} \rightarrow \mathrm{CaC}_{2} \mathrm{O}_{4}+\mathrm{H}_{2} \mathrm{O}
$$

\subsection{Mehanokemijska sinteza s kalcijevim kloridom, $\mathrm{CaCl}_{2} \cdot 2 \mathrm{H}_{2} \mathrm{O}$}

Slika 2 prikazuje spektre IR uzoraka dobivenih reakcijom kalcijeva klorida i natrijeva oksalata. Rezultati upućuju na to da pri svim brzinama mljevenja (250, 500 i 750 o min $^{-1}$ ) nastaje isključivo najstabilniji oblik COM. 


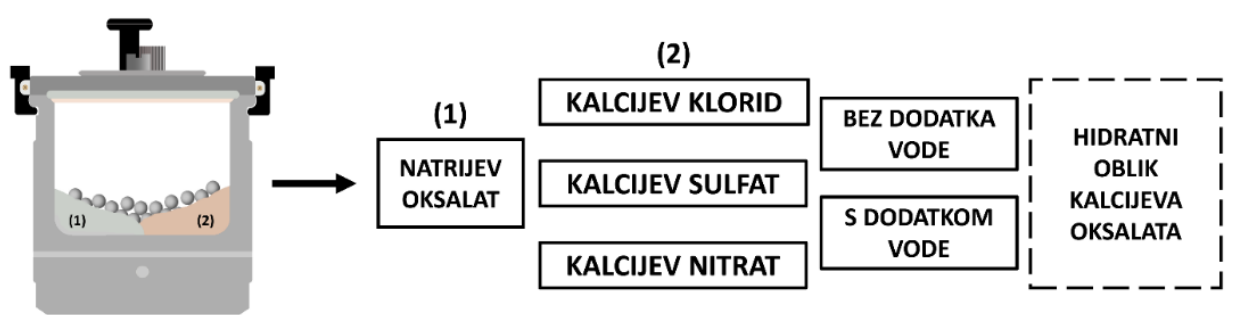

Slika 1 - Jednostavna shema mehanokemijske sinteze kristala kalcijeva oksalata

Fig. 1 - Simplified scheme of the mechanochemical synthesis of calcium oxalate crystals

Tablica 1 - Karakteristične vrpce standarda COM i njihova asignacija u spektru ${ }^{14,17,18}$ IR

Table 1 - Characteristic FTIR transmittance peaks and their assignments for COM standard sample ${ }^{14,17,18}$

\begin{tabular}{l|l}
\hline $\mathrm{COM} / \mathrm{cm}^{-1}$ & $\begin{array}{l}\text { Asignacija } \\
\text { Assignment }\end{array}$ \\
\hline 3481 & \multicolumn{1}{|l}{ asimetrično i simetrično istezanje koordinirane vode $(\mathrm{O}-\mathrm{H}$ istezanje) } \\
3331 & asymmetric and symmetrical stretching of coordinated water $(\mathrm{O}-\mathrm{H}$ stretching $)$ \\
3240 & asimetrično karbonilno istezanje $v_{\text {as }}\left(\mathrm{COO}^{-}\right)$ \\
3061 & asymmetric carbonyl stretch $v_{\text {as }}\left(\mathrm{COO}^{-}\right)$ \\
1618 & simetrično karbonilno istezanje i metal-karbonilno istezanje $v_{\mathrm{s}}\left(\mathrm{COO}^{-}\right)$ \\
1317 & symmetrical carbonyl stretching and metal-carbonyl stretching $v_{\mathrm{s}}\left(\mathrm{COO}^{-}\right)$ \\
948 & $\mathrm{H}-\mathrm{O}-\mathrm{H}$ svijanje \\
885 & $\mathrm{H}-\mathrm{O}-\mathrm{H}$ bending \\
781 & $\mathrm{O}-\mathrm{C}-\mathrm{O}$ asimetrično njihanje \\
653 & $\mathrm{O}-\mathrm{C}-\mathrm{O}$ asymmetric swinging \\
515 & $\mathrm{O}-\mathrm{C}-\mathrm{O}$ asimetrično mahanje \\
\hline
\end{tabular}

Analizom uzorka nakon $1 \mathrm{~h}$ i pri najmanjoj brzini mljevenja (250 o $\mathrm{min}^{-1}$ ) uočeno je zaostajanje reaktanta, što se posebice uočava u području $\mathrm{O}-\mathrm{H}$ istezanja $\left(3500-3000 \mathrm{~cm}^{-1}\right)$ u uzorku bez dodatka vode i prije ispiranja (slika 2 (a)). Također se prisutnost polaznog reaktanta može zapaziti pojavom vrpce na približno $2148 \mathrm{~cm}^{-1}$. Pri završetku reakcije (nakon $2 \mathrm{~h}$ ) u uzorku prije ispiranja uočene su oštrije vrpce COM u području $\mathrm{O}-\mathrm{H}$ istezanja samo u uzorcima s dodatkom vode, a posebno se raspoznaje karakteristična vrpca za COM na približno $3491 \mathrm{~cm}^{-1}$. U uzorcima bez dodatka vode i dalje zaostaje veća količina polaznog reaktanta. Svi uzorci ispitani su kvalitativnom analitičkom metodom kako bi se utvrdila čistoća uzorka. Prisutnost kloridnih iona dokazivala se dodatkom $\mathrm{AgNO}_{3}$ i pojavom bijelog taloga $\mathrm{AgCl}$. Pozitivna reakcija upućivala je na produkte manje čistoće te potrebu daljnjeg ispiranja sintetiziranog uzorka.
Analizom uzoraka nakon $1 \mathrm{~h}$ sinteze i nakon ispiranja na spektru IR uočena je široka vrpca u području $3500-3000 \mathrm{~cm}^{-1}$, što i dalje upućuje na produkt manje čistoće i prisutnost polaznog reaktanta, dok se nakon $2 \mathrm{~h}$ sinteze u uzorcima bez dodatka i s dodatkom vode pojavljuju oštrije i intenzivnije vrpce u području $\mathrm{O}-\mathrm{H}$ istezanja i otiska prsta, posebice vrpca na $3491 \mathrm{~cm}^{-1}$ te ostale karakteristične vibracije za COM. Slično ponašanje

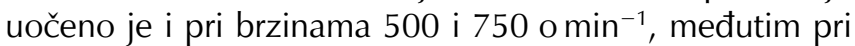
najvećoj brzini (750 o $\mathrm{min}^{-1}$ ) uočeno je brže nastajanje produkta pojavom intenzivnijih vrpci u području 3500 - $3000 \mathrm{~cm}^{-1}$ čak i nakon 1 h sinteze. Nakon ispiranja uzoraka sintetiziranih pri najvećoj brzini mljevenja rezultati spektroskopije IR upućuju na dobivanje produkta visoke čistoće. 

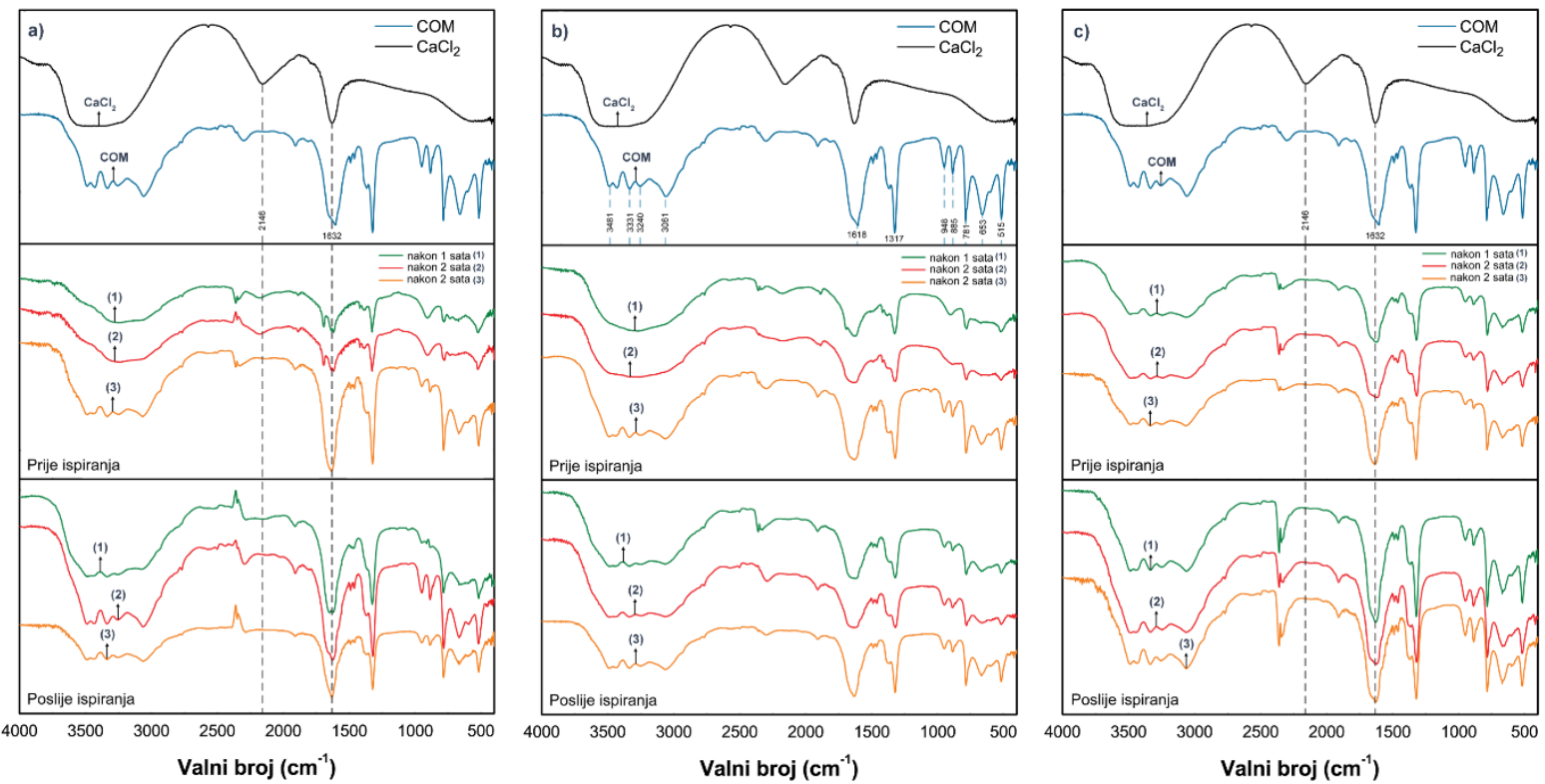

Slika 2 - Spektri IR sintetiziranih uzoraka pri brzinama: a) $250 \mathrm{o} \mathrm{min}^{-1}$, b) $500 \mathrm{o} \mathrm{min}^{-1}$ i c) $750 \mathrm{o} \mathrm{min}^{-1}$ uspoređenih sa spektrom IR standarda COM i reaktanta $\mathrm{CaCl}_{2}$

Fig. 2 - IR spectra of synthesized samples at milling speeds of a) $250 \mathrm{rpm}$, b) $500 \mathrm{rpm}$, and c) $750 \mathrm{rpm}$. Results were compared with both IR spectra of $\mathrm{COM}$ standard sample and starting material $\mathrm{CaCl}_{2}$.

Tablica - Rezultati termogravimetrijske analize uzoraka $\left(t_{0}\right.$ - početna temperature razgradnje, $t_{\max }-$ temperatura pri maksimalnoj brzini razgradnje, $t_{\mathrm{e}}$ - temperatura kraja razgradnje, $\Delta m$ - gubitak mase)

Table 2 - Results of the thermogravimetric analysis of the sample $\left(t_{0}-\right.$ initial degradation temperature, $t_{\max }-$ temperature of maximum degradation rate, $t_{\mathrm{e}}$ - end of degradation temperature, $\Delta m$ - loss of mass)

\begin{tabular}{l|l|l|l|l|l|l|l}
\hline \multicolumn{2}{l}{} & $\begin{array}{l}\text { Brzina mljevenja } \\
\text { Milling speed }\end{array}$ & $t_{0} /{ }^{\circ} \mathrm{C}$ & $t_{\max } /{ }^{\circ} \mathrm{C}$ & $t_{\mathrm{e}} /{ }^{\circ} \mathrm{C}$ & $\Delta \mathrm{m} / \mathrm{mg}$ & $\Delta \mathrm{m} / \%$ \\
\hline $\begin{array}{l}\text { Poslije } \\
\text { ispiranja }\end{array}$ & s dodatkom vode & 250 & 78,35 & 224,93 & 166,51 & 2,69 & 12,10 \\
uzoraka & with addition of & 500 & 73,20 & 223,49 & 165,68 & 2,43 & 11,82 \\
After & water & 750 & 76,93 & 225,07 & 167,25 & 2,64 & 12,62 \\
sample & bez dodatka vode & 250 & 72,77 & 231,91 & 166,50 & 2,64 & 13,25 \\
washing & without addition of & 500 & 73,63 & 243,08 & 169,84 & 2,49 & 12,37 \\
& water & 750 & 75,56 & 221,83 & 167,16 & 2,22 & 11,64 \\
\hline
\end{tabular}
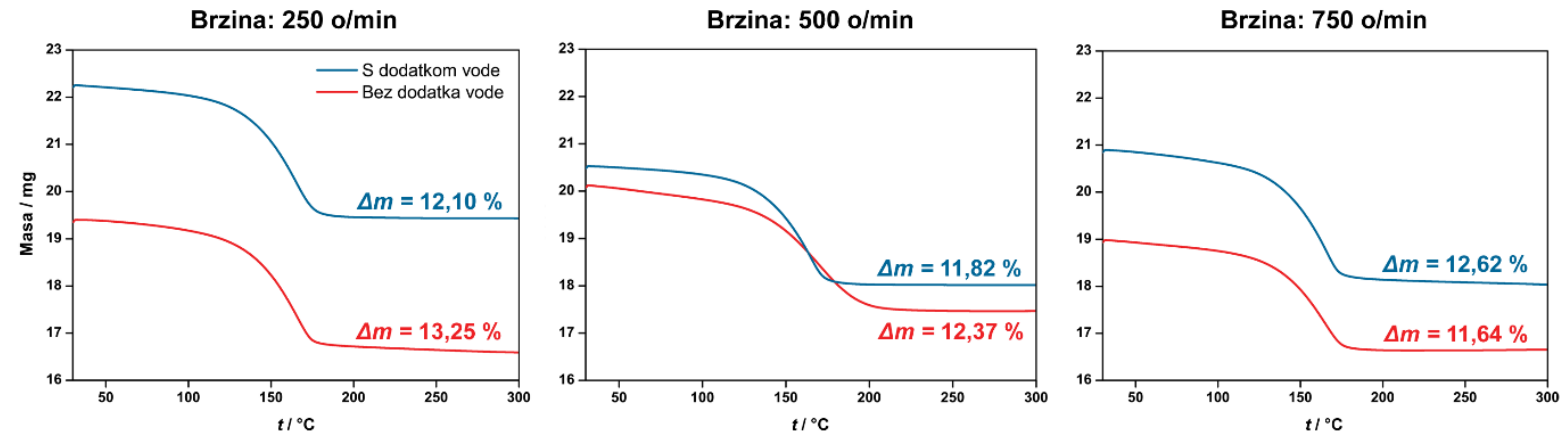

Slika 3 - Termogrami uzoraka sintetiziranih pri svim brzinama mljevenja polaznog reaktanta $\mathrm{CaCl}_{2}(\Delta m$ - gubitak mase)

Fig. 3 - Thermograms of the samples synthesized from the starting material $\mathrm{CaCl}_{2}$ by modulating milling speed ( $\Delta m-$ loss of mass) 
$\mathrm{Na}$ slici 3 i u tablici 2 prikazani su rezultati termogravimetrijske analize uzoraka s dodatkom i bez dodatka vode pri svim brzinama mljevenja. Prema rezultatima uočeno je da gubitak mase vode započinje i završava u približno jednakom temperaturnom rasponu $\left(t_{0}=75,07 \pm 2,25{ }^{\circ} \mathrm{C} ; \quad t_{\mathrm{e}}=167,16 \pm 1,43{ }^{\circ} \mathrm{C}\right) . \quad \mathrm{U}$ svim uzorcima nastaje željeni hidratni oblik, COM.

Kao što se može primijetiti u tablici 2 značajnije razlike u postotku gubitka mase nisu uočene, prosječno odstupanje iznosi 0,59 i varijabilitet je nizak (4,76 \%).

Morfologija uzoraka te njihova raspodjela ispitana je svjetlosnom mikroskopijom i metodom DLS. Slika 4 prikazuje snimke uzoraka dobivenih nakon $2 \mathrm{~h}$ sinteze pri svim brzinama u obje serije (s dodatkom i bez dodatka vode). Morfologiju kristala nije moguće odrediti optičkom mikroskopijom zbog izrazito malih i agregiranih čestica. Mikrografije pokazuje da se povećanjem brzine mljevenja dobivaju manje čestice. To potvrđuju rezultati DLS-a koji pokazuju da se u uzorcima dobivenim pri najmanjoj i najvećoj brzini mljevenja uz dodatak vode javlja bimodalna raspodjela veličine čestica. Povećanjem brzine mljevenja veličina čestica se smanjuje (250 o min ${ }^{-1}$ : $d=1922,5 \pm 51,62 \mathrm{~nm} ; \quad 750$ o min $^{-1}, \quad d=1682,2 \pm$ $272,36 \mathrm{~nm}$, slika $\left.4\left(\mathrm{~d}^{*}\right) \mathrm{i}\left(\mathrm{f}^{*}\right)\right)$. Također, pri najvećoj brzini mljevenja uočava se šira raspodjela veličina čestica u odnosu na dobivenu raspodjelu pri brzini $250 \mathrm{o} \mathrm{min}^{-1}$, što upućuje na nastajanje nehomogenijeg sustava. Veće čestice predstavljaju agregirane čestice koje nisu u potpunosti dispergirane $\left(d\left(250 \mathrm{o} \mathrm{min}^{-1}\right)=5590,12 \mathrm{~nm}\right.$, $d\left(750\right.$ o min $\left.\left.^{-1}\right)=5379,75 \mathrm{~nm}\right)$.
Brzina: 250 o/min
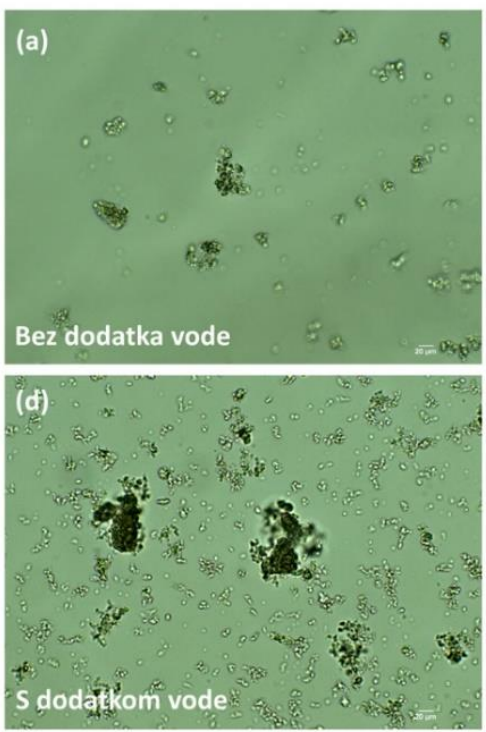

\section{Brzina: 500 o/min}
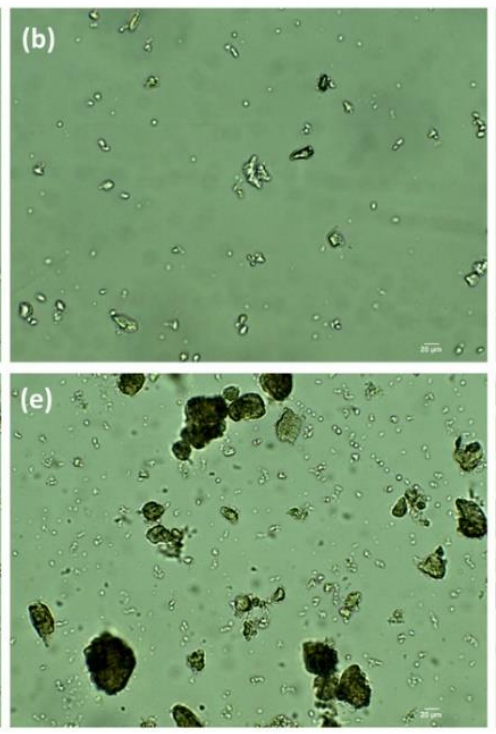

Brzina: 750 o/min
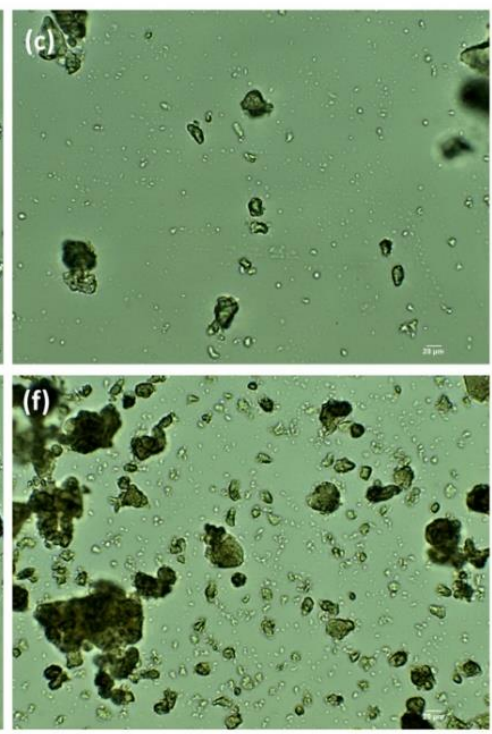
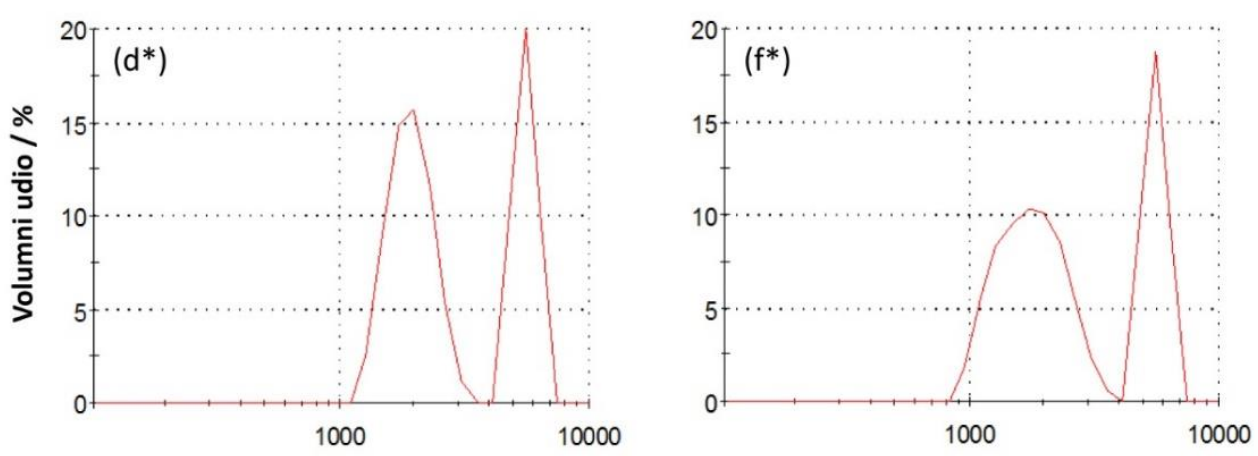

$d / \mathrm{nm}$

Slika 4 - Snimke svjetlosne mikroskopije kristala hidrata kalcijeva oksalata u obje serije sinteze pri svim brzinama mljevenja (bez dodatka a), b) i c) i s dodatkom vode d), e) i f)) i raspodjela veličine čestica pri (d*) 250 o min ${ }^{-1}$ i (f*) 750 o min ${ }^{-1}$

Fig. 4 - Calcium oxalate crystals light microscopy images in both synthesis series at all milling speeds (without a), b), and c) and with addition of water d), e), and f)), and particle size distribution at (d*) $250 \mathrm{rpm}$ and (f*) $750 \mathrm{rpm}$ 


\subsection{Mehanokemijska sinteza s kalcijevim sulfatom, $\mathrm{CaSO}_{4} \cdot 2 \mathrm{H}_{2} \mathrm{O}$}

Strukturalna svojstva sintetiziranih uzoraka dobivenih mehanokemijskom sintezom kalcijeva sulfata i natrijeva oksalata ispitana su spektroskopijom FTIR te su rezultati prikazani na slici 5. Napravljena je usporedba uzoraka analiziranih nakon $1 \mathrm{~h}$ sinteze, prije i poslije ispiranja te nakon $2 \mathrm{~h}$ iz obje serije sinteza pri svim primijenjenim brzinama mljevenja. Iz dobivenih rezultata pri najmanjoj brzini $\left(250 \mathrm{o} \mathrm{min}^{-1}\right)$ u svim uzorcima prije ispiranja vidljive su široke vrpce u području $\mathrm{O}-\mathrm{H}$ istezanja te široka vrpca u području otiska prsta s karakterističnom vrpcom na približno $1122 \mathrm{~cm}^{-1}$, koja odgovara asimetričnom istezanju skupina $\mathrm{SO}_{4}{ }^{2-}$ te na $1004 \mathrm{~cm}^{-1}$, koja odgovara simetričnom istezanju skupina $\mathrm{SO}_{4}{ }^{2-} \cdot{ }^{19}$ Također se uočava $\mathrm{H}-\mathrm{O}-\mathrm{H}$ istezanje polaznog reaktanta na približno $2112 \mathrm{~cm}^{-1}$. Iz rezultata se može vidjeti da je u uzorcima obje serije dobiven produkt manje čistoće. Nakon $1 \mathrm{~h}$ uočavaju se karakteristične vrpce COM, no vrpce postaju oštrije i intenzivnije tek nakon $2 \mathrm{~h}$ sinteze, dok se produkti veće čistoće uočavaju u uzorcima s dodatkom vode. Vrpce pri $1004 \mathrm{~cm}^{-1}, 1122 \mathrm{~cm}^{-1}$ i $2112 \mathrm{~cm}^{-1}$ upućuju na zaostajanje sulfata. Reaktant se uklanja ispiranjem velikom količinom deionizirane vode. Povećanjem brzine mljevenja već nakon $1 \mathrm{~h}$ sinteze uočavaju se vrpce COM uz zaostajanje polaznog reaktanta, što se posebice uočava pri najvećoj brzini $\left(750 \mathrm{o} \mathrm{min}^{-1}\right)$.

Nakon ispiranja uzoraka uočavaju se oštrije vrpce COM, dok vrpce sulfata više nisu prisutne na IR-spektru. Kako bi se utvrdila čistoća uzorka, provedena je kvalitativna analiza
S reagensom $\mathrm{Ba}\left(\mathrm{NO}_{3}\right)_{2}$ da bi se dokazala prisutnost sulfatnih iona. $\mathrm{U}$ reakciji $\mathrm{Ba}\left(\mathrm{NO}_{3}\right)_{2}$ i sulfatnih iona nastaje bijeli talog $\mathrm{BaSO}_{4}$ koji upućuje na potrebu daljnjeg ispiranja uzorka.

Isprani uzorci nakon $2 \mathrm{~h}$ sinteze ispitani su termogravimetrijskom analizom te je utvrđena prisutnost COM u obje serije sinteza. $U$ tablici 3 prikazani su rezultati termogravimetrijske analize koji ukazuju na gubitak mase $(\Delta m)$ u jednom koraku približne vrijednosti jedne molekule vode. Gubitak mase započinje i završava u približno jednakom temperaturnom rasponu $\left(t_{0}=79,38 \pm 1,59{ }^{\circ} \mathrm{C}\right.$; $\left.t_{\mathrm{e}}=170,24 \pm 1,50{ }^{\circ} \mathrm{C}\right)$.

Značajnije razlike u gubitku mase nisu uočene povećanjem brzine mljevenja, što potvrđuje prisutnost isključivo COM u svim uzorcima. Prosječno odstupanje iznosi 0,60 i varijabilitet je nizak $(4,70 \%)$.

Na temelju mikroskopskih snimki (slika 6) i metode DLS (slike $6\left(\mathrm{~d}^{*}\right)$ i $\left.\left(\mathrm{f}^{*}\right)\right)$ procijenjena je raspodjela veličina čestica. Rezultati upućuju na to da se u seriji sinteze bez dodatka vode, veličina čestica smanjuje povećanjem brzine mljevenja s tendencijom stvaranja agregata. Pojava agregacije posebno je izražena u seriji s dodatkom vode (vidi slike $6\left(d^{*}\right)$ i $\left(f^{*}\right)$ ). Naime, izmjerene vrijednosti uzoraka dispergiranih čestica u seriji s dodatkom vode upućuju na bimodalnu raspodjelu čestica pri obje

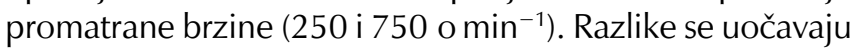
u uzorcima sintetiziranih pri brzini od $250 \mathrm{o} \mathrm{min}^{-1}$, gdje je vidljiva šira raspodjela veličina čestica uz moguću pojavu agregata pri obje brzine mljevenja.
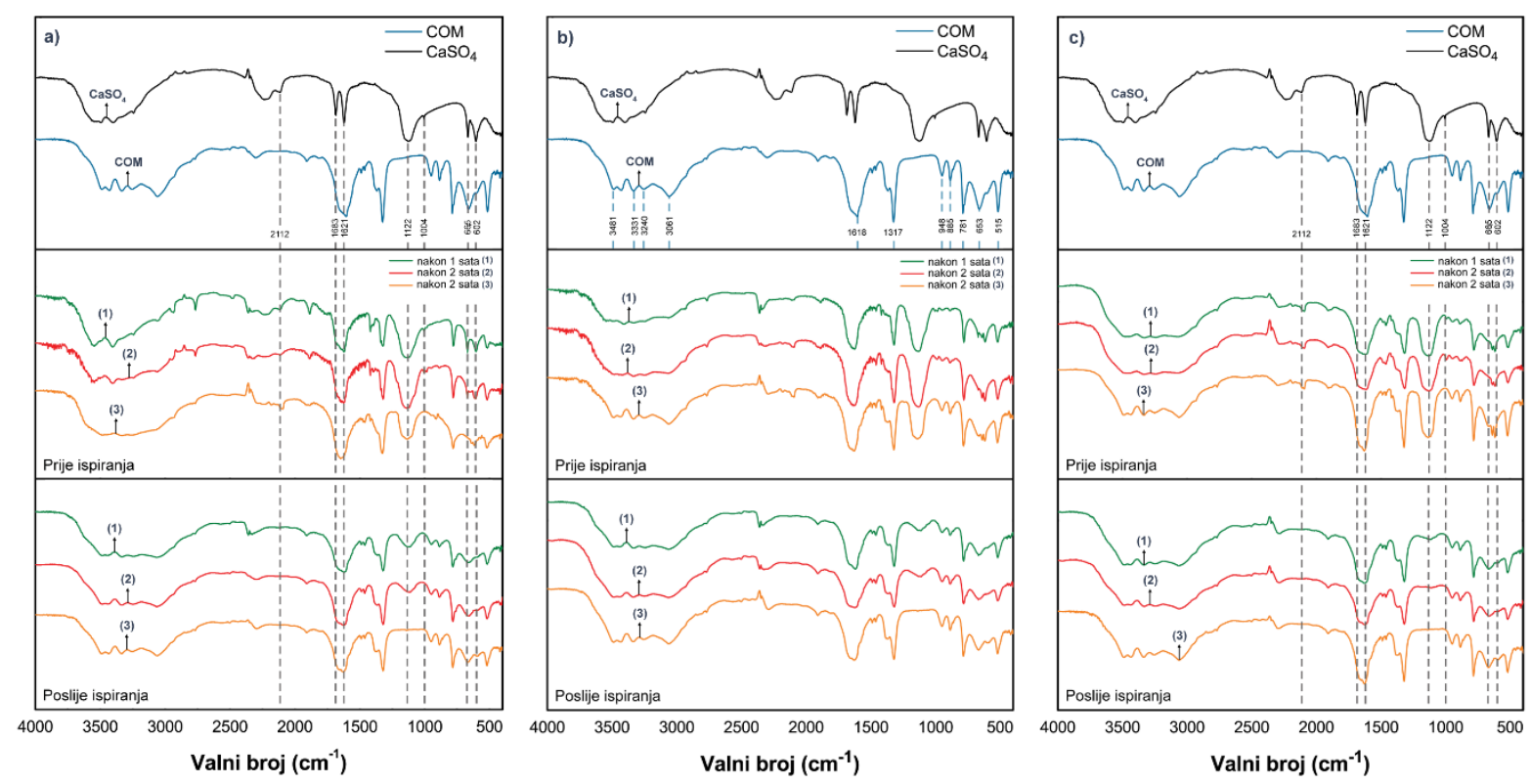

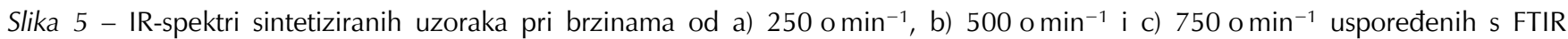
spektrom standarda COM i reaktanta $\mathrm{CaSO}_{4}$

Fig. 5 - IR spectra of synthesized samples at milling speeds a) $250 \mathrm{rpm}$, b) $500 \mathrm{rpm}$, and c) $750 \mathrm{rpm}$. Results were compared with both FTIR spectra of COM standard sample and starting material $\mathrm{CaSO}_{4}$ 
Tablica 3 - Rezultati termogravimetrijske analize uzoraka $\left(t_{0}\right.$ - početna temperature razgradnje, $t_{\max }$ - temperatura pri maksimalnoj brzini razgradnje, $t_{\mathrm{e}}$ - temperatura kraja razgradnje, $\Delta m$ - gubitak mase)

Table 3 - Results of the thermogravimetric analysis of the sample $\left(t_{0}\right.$ - initial degradation temperature, $t_{\max }$ - temperature of maximum degradation rate, $t_{\mathrm{e}}$ - end of degradation temperature, $\Delta m$ - loss of mass)

\begin{tabular}{l|l|c|c|c|c|c|c}
\hline \multicolumn{2}{l|}{} & $\begin{array}{c}\text { Brzina mljevenja } \\
\text { Milling speed }\end{array}$ & $t_{0} /{ }^{\circ} \mathrm{C}$ & $t_{\max } /{ }^{\circ} \mathrm{C}$ & $t_{\mathrm{e}} /{ }^{\circ} \mathrm{C}$ & $\Delta \mathrm{m} / \mathrm{mg}$ & $\Delta \mathrm{m} / \%$ \\
\hline $\begin{array}{l}\text { Poslije } \\
\text { ispiranja }\end{array}$ & s dodatkom vode & 250 & 81,57 & 168,79 & 243,87 & 3,07 & 13,43 \\
uzoraka & with addition of & 500 & 79,38 & 170,46 & 242,76 & 2,97 & 11,96 \\
After & water & 750 & 80,16 & 168,96 & 241,71 & 2,99 & 12,04 \\
sample & bez dodatka vode & 250 & 80,04 & 169,45 & 243,47 & 3,11 & 12,96 \\
washing & without addition of & 500 & 77,49 & 172,72 & 241,13 & 3,01 & 13,13 \\
& water & 750 & 77,61 & 171,08 & 240,56 & 2,99 & 12,87 \\
\hline
\end{tabular}

Brzina: 250 o/min
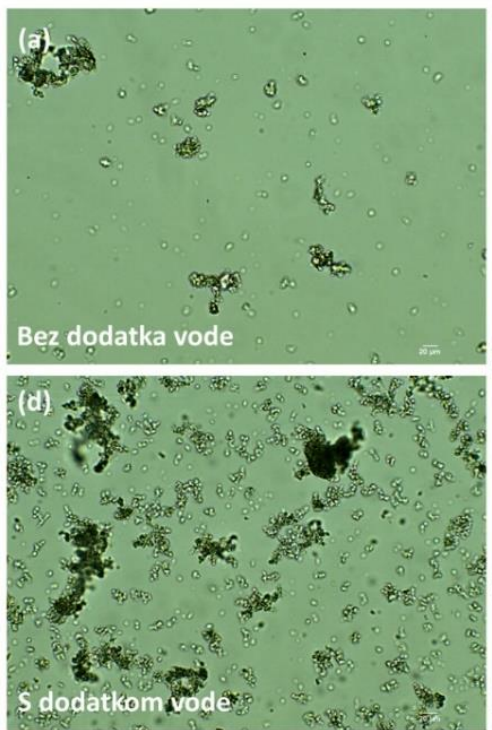

Brzina: $500 \mathrm{o} / \mathrm{min}$
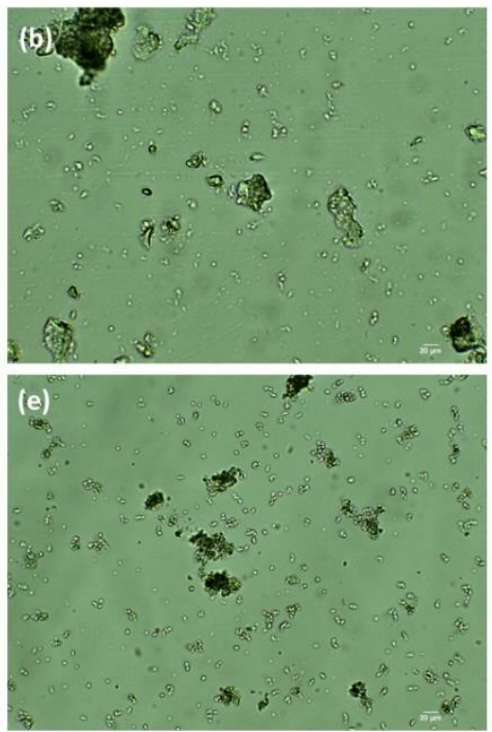

Brzina: 750 o/min
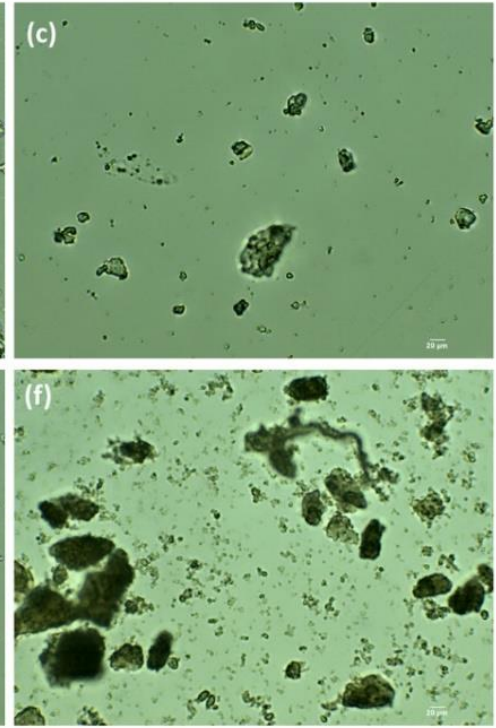
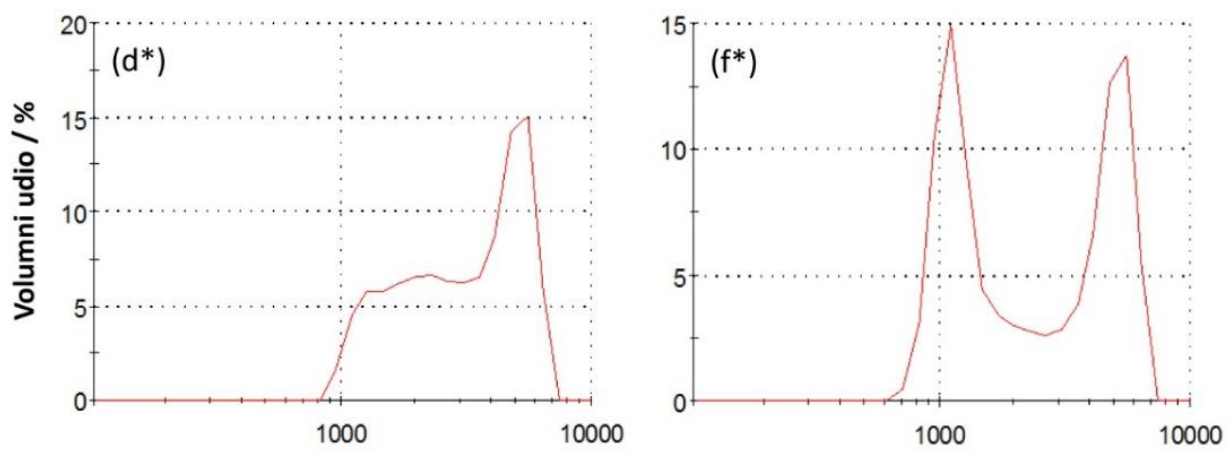

$d / \mathrm{nm}$

Slika 6 - Snimke svjetlosne mikroskopije kristala hidrata kalcijeva oksalata u obje serije sinteze pri svim brzinama mljevenja (bez dodatka a), b) i c) i s dodatkom vode d), e) i f)) i raspodjela veličine čestica pri (d*) 250 o min ${ }^{-1}$ i ( $\left.f^{*}\right) 750$ o min m $^{-1}$

Fig. 6 - Calcium oxalate crystals light microscopy images in both synthesis series at all milling speeds (without a), b), and c), and with addition of water d), e), and f)), and particle size distribution at ( $\left(^{*}\right) 250 \mathrm{rpm}$ and ( $\left.\mathrm{f}^{*}\right) 750 \mathrm{rpm}$ 
Srednja vrijednost promjera čestica pri brzini 250 o min $^{-1}$ je $d=1853,6 \pm 277,92 \mathrm{~nm}$, a pri brzini $750 \mathrm{o} \mathrm{min}^{-1}$ ona iznosi $d=1498,0 \pm 369,29 \mathrm{~nm}$. Drugi maksimum, bez vidljive oštrije granice s prvim maksimumom, označava agregirane čestice koje nisu u potpunosti dispergirane $\left(d\left(250\right.\right.$ o $\left.\min ^{-1}\right)=4835,2 \mathrm{~nm}$,

$\left.d\left(750{\text { o } \text { min }^{-1}}^{-1}\right)=4276,7 \mathrm{~nm}\right)$.

\subsection{Mehanokemijska sinteza s kalcijevim nitratom, $\mathrm{Ca}\left(\mathrm{NO}_{3}\right)_{2} \cdot 4 \mathrm{H}_{2} \mathrm{O}$}

IR-spektri uzoraka sintetiziranih reakcijom natrijeva oksalata i kalcijeva nitrata prikazani su na slici 7. Pri najmanjoj brzini (250 o min $^{-1}$ ) (slika 7 a)) pojavljuje se oštrija vrpca na $1045 \mathrm{~cm}^{-1}$ koja odgovara simetričnom istezanju nitratnog iona. ${ }^{20}$ Upravo se prema pojavi vrpce na $1045 \mathrm{~cm}^{-1}$ mogla utvrditi prisutnost zaostalog reaktanta. Navedena vrpca se ne pojavljuje nakon ispiranja uzorka. Na zaostajanje reaktanta također upućuje i pojava široke vrpce u području $\mathrm{O}-\mathrm{H}$ istezanja. Prije ispiranja uzoraka i nakon $1 \mathrm{~h}$ sinteze u seriji bez dodatka vode vrpca na $1045 \mathrm{~cm}^{-1}$ posebno je izražena te se pojavljuje široka vrpca u području $\mathrm{O}-\mathrm{H}$ istezanja. Nakon 2 h sinteze u seriji bez dodatka vode i dalje su izražene vrpce reaktanta, dok se $u$ uzorku s dodatkom vode počinju pojavljivati karakteristične vrpce $\mathrm{COM}$ u području $\mathrm{O}-\mathrm{H}$ istezanja. Vrpca na $1045 \mathrm{~cm}^{-1}$ nestaje, a nazire se pojavljivanje vrpce na $1317 \mathrm{~cm}^{-1}$ (karakteristična vrpca za COM).
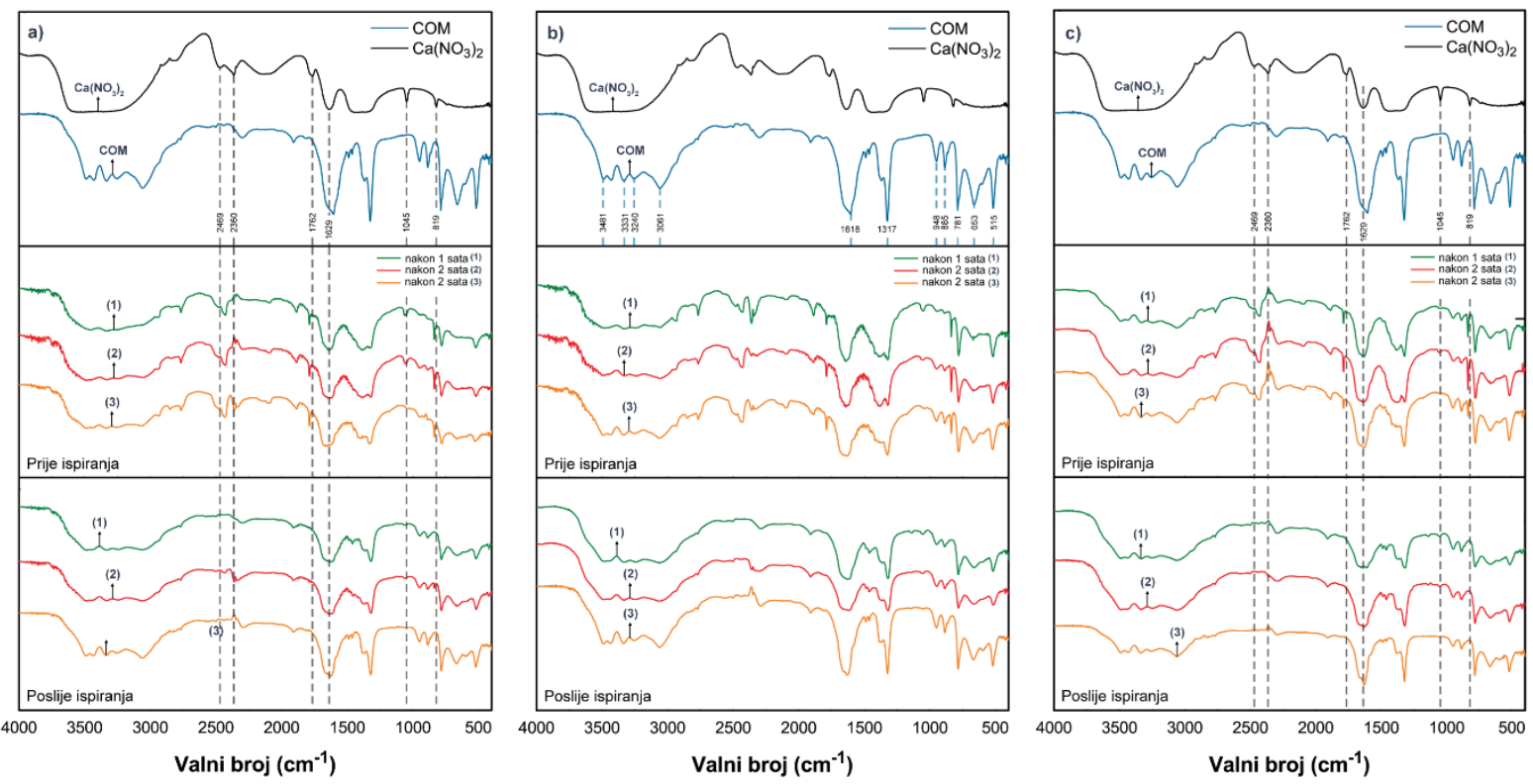

Slika 7 - IR-spektri sintetiziranih uzoraka pri brzinama od a) $250 \mathrm{o} \mathrm{min}^{-1}$, b) $500 \mathrm{o} \mathrm{min}^{-1}$ i c) 750 o min ${ }^{-1}$ uspoređenih s IR-spektrom COM standarda i reaktanta $\mathrm{Ca}\left(\mathrm{NO}_{3}\right)_{2}$

Fig. 7 - IR spectra of synthesized samples at milling speeds a) $250 \mathrm{rpm}$, b) $500 \mathrm{rpm}$, and c) $750 \mathrm{rpm}$. Results were compared with both IR spectra of COM standard sample and starting material $\mathrm{Ca}\left(\mathrm{NO}_{3}\right)_{2}$.

Tablica 4 - Rezultati termogravimetrijske analize uzoraka ( $t_{0}$ - početna temperature razgradnje, $t_{\max }$ - temperatura pri maksimalnoj brzini razgradnje, $t_{\mathrm{e}}$ - temperatura kraja razgradnje, $\Delta m$ - gubitak mase)

Table 4 - Results of the thermogravimetric analysis of the sample $\left(t_{0}-\right.$ initial degradation temperature, $t_{\max }-$ temperature of maximum degradation rate, $t_{\mathrm{e}}$ - end of degradation temperature, $\Delta m$ - loss of mass)

\begin{tabular}{l|l|c|c|c|c|c|c}
\hline \multicolumn{2}{l|}{} & $\begin{array}{c}\text { Brzina mljevenja } \\
\text { Milling speed }\end{array}$ & $t_{0} /{ }^{\circ} \mathrm{C}$ & $t_{\max } /{ }^{\circ} \mathrm{C}$ & $t_{\mathrm{e}} /{ }^{\circ} \mathrm{C}$ & $\Delta \mathrm{m} / \mathrm{mg}$ & $\Delta m / \%$ \\
\hline $\begin{array}{l}\text { Poslije } \\
\text { ispiranja }\end{array}$ & S dodatkom vode & 250 & 77,44 & 166,45 & 241,38 & 2,65 & 12,43 \\
uzoraka & With addition of & 500 & 76,09 & 170,61 & 242,99 & 2,77 & 11,78 \\
After & water & 750 & 77,58 & 171,22 & 242,99 & 2,84 & 11,76 \\
sample & bez dodatka vode & 250 & 77,73 & 158,91 & 241,55 & 1,94 & 8,25 \\
washing & Without addition of & 500 & 78,79 & 169,48 & 243,30 & 2,77 & 11,77 \\
& water & 750 & 77,26 & 167,64 & 243,66 & 2,62 & 11,81 \\
\hline
\end{tabular}


Uzorci su ispitani kvalitativnom analitičkom metodom kako bi se utvrdila čistoća uzorka. Nitratni ioni dokazivani su $1 \%$-tnom otopinom difenilamina, a pojava plavog prstena ukazivala je na prisutnost nitratnog iona.

Nakon ispiranja uzoraka dobivenih pri brzini mljevenja od 250 o min $^{-1}$ uočavaju se oštrije i intenzivnije vrpce COM bez prisutnosti vrpci nitrata. Nakon $2 \mathrm{~h}$ sinteze u seriji s dodatkom vode IR-spektar upućuje na uzorak visoke čistoće COM. IR-spektri uzoraka sintetiziranih pri brzini mljevenja od $500 \mathrm{o} \mathrm{min}^{-1}$ pokazuju slično ponašanje. Poslije ispiranja uzoraka i nakon $2 \mathrm{~h}$ sinteze u seriji $\mathrm{s}$ dodatkom vode uočavaju se intenzivnije vrpce u području $\mathrm{O}-\mathrm{H}$ istezanja te oštrije vrpce na približno $1618 \mathrm{~cm}^{-1} \mathrm{i}$ $1317 \mathrm{~cm}^{-1}$ bez pojave vrpci nitrata. Pri brzini mljevenja od
750 o min $^{-1}$ oštrije vrpce COM uočavaju se čak i nakon $1 \mathrm{~h}$ sinteze, dok se produkt visoke čistoće može dobiti i prije ispiranja uzorka $\mathrm{i}$ nakon $2 \mathrm{~h}$ sinteze $\mathrm{u}$ seriji $\mathrm{s}$ dodatkom vode.

Isprani i osušeni uzorci obje serije nakon $2 \mathrm{~h}$ sinteze i pri svim primijenjenim brzinama mljevenja analizirani su termogravimetrijskom analizom (tablica 4) kako bi se utvrdio kvantitativni sastav pojedinog uzorka. Rezultati ukazuju na prisutnost COM. U sintezi kalcijeva oksalata s nitratom uočen je najmanji gubitak mase pri brzini od 250 o min $^{-1} \mathrm{u}$ odnosu na prethodne sinteze, što bi moglo ukazivati na veće zaostajanje reaktanta u uzorku. Prosječno odstupanje iznosi 1,52 i varijabilitet je nizak $(13,42 \%)$.
Brzina: $250 \mathrm{o} / \mathrm{min}$
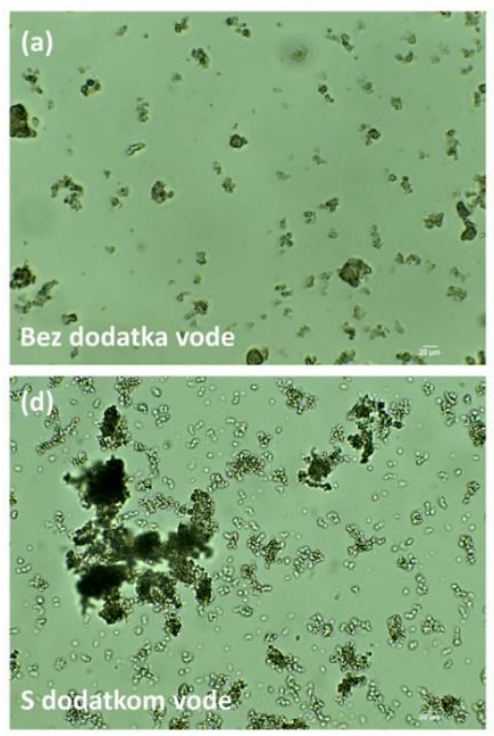

Brzina: 500 o/min
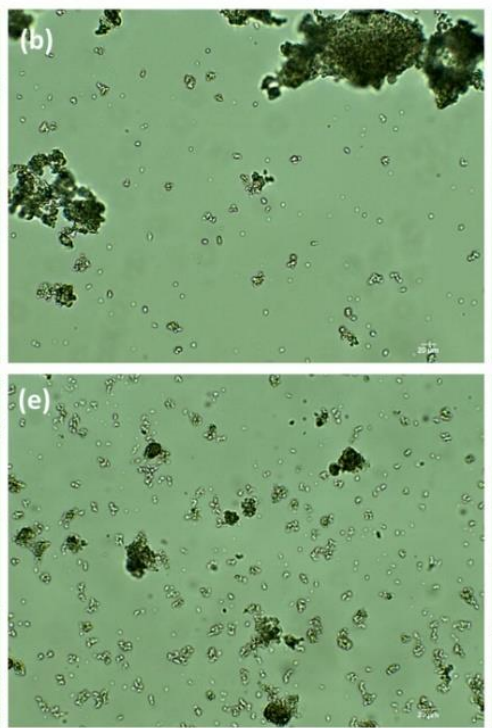

Brzina: 750 o/min
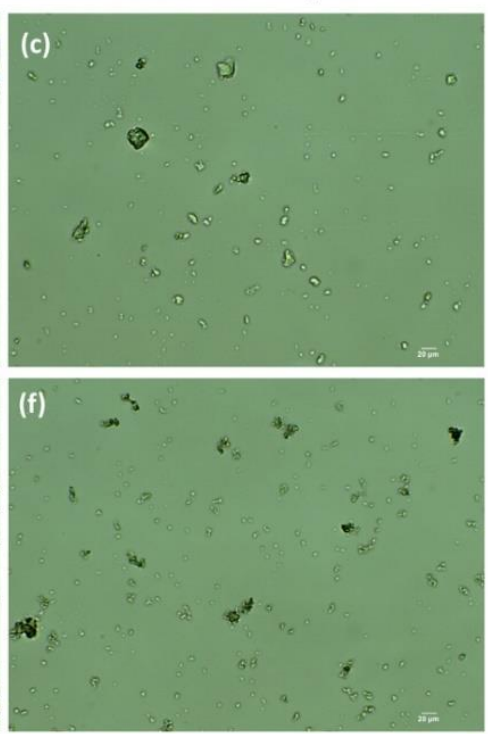
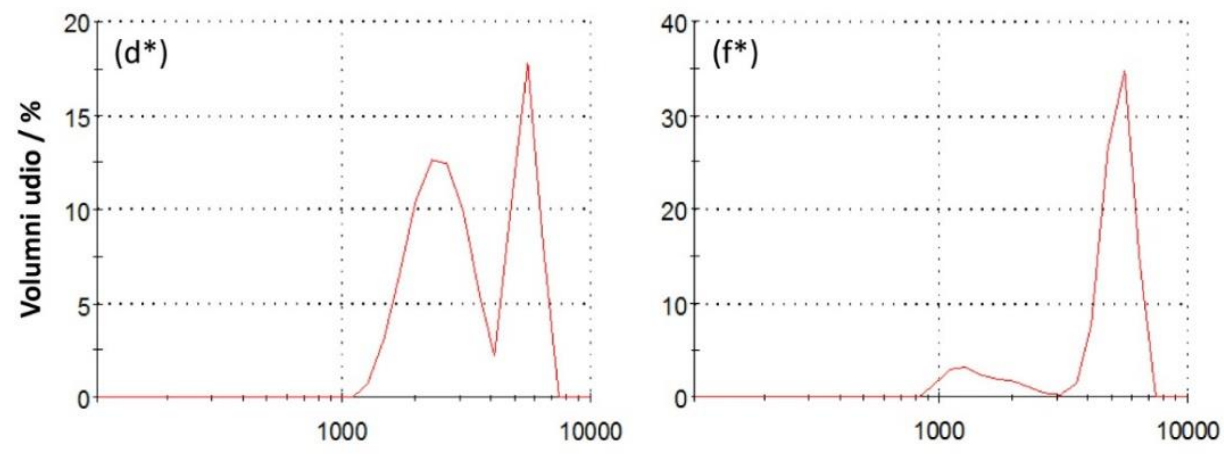

$d / \mathrm{nm}$

Slika 8 - Snimke svjetlosne mikroskopije kristala hidrata kalcijeva oksalata u obje serije sinteze pri svim brzinama mljevenja (bez dodatka a), b) i c) i s dodatkom vode d), e) i f)) i raspodjela veličine čestica pri (d*) 250 o min ${ }^{-1}$ i (f*) 750 o min ${ }^{-1}$

Fig. 8 - Calcium oxalate crystals light microscopy images in both synthesis series at all milling speeds (without a), b), and c), and with addition of water $d), e)$, and f)), and particle size distribution at ( $\left.d^{*}\right) 250 \mathrm{rpm}$ and (f*) $750 \mathrm{rpm}$ 
Snimke dobivene svjetlosnom mikroskopijom i raspodjele veličine čestica sintetiziranih uzoraka $s$ polaznim reaktantom kalcijeva nitrata prikazane su na slici 8 . U seriji sinteza bez dodatka vode i pri najmanjoj brzini od 250 o min $^{-1}$ uočavaju se nešto veće čestice u odnosu na čestice dobivene pri brzini mljevenja od $500 \mathrm{o} \mathrm{min}^{-1}$, dok se znatno manje čestice uočavaju pri brzini od 750 o in $^{-1}$. Slično ponašanje vidljivo je i s dodatkom vode, dok se u ovoj seriji sinteze uočavaju i agregati čestica. Morfologiju kristala niti u jednom slučaju nije moguće odrediti zbog manjih veličina čestica.

Metodom DLS utvrđena je bimodalna i šira raspodjela veličina čestica pri obje brzine mljevenja uz moguću prisutnost agregata što se vidi i mikroskopskom analizom (slike $8\left(\mathrm{~d}^{*}\right)$ i $\left.\left(\mathrm{f}^{*}\right)\right)$. Izmjerene srednja vrijednost promjera čestica pri brzini 250 o min $^{-1}$ je $d=2246,5 \pm 607,48 \mathrm{~nm}$ i pri $750 \mathrm{o} \mathrm{min}^{-1}$ iznosi $d=1589,5 \pm 149,92 \mathrm{~nm}$. Drugi maksimum (bez vidljive granice s prvim maksimumom pri najmanjoj brzini), kao i u dosadašnjim analizama vjerojatno označava agregirane čestice koje nisu u potpunosti dispergirane $\left(d\left(250 \mathrm{o} \mathrm{min}^{-1}\right)=5442,0 \mathrm{~nm}\right.$, $d\left(750\right.$ o $\left.\left.\mathrm{min}^{-1}\right)=4866,5 \mathrm{~nm}\right)$.

\section{Zaključak}

Mehanokemijskom sintezom kalcijeva oksalata iz tri soli kalcija (klorid, sulfat i nitrat) s natrijevim oksalatom uspješno je sintetiziran kalcijev oksalat monohidrat (COM). Pri najmanjoj brzini $\left(250 \mathrm{o} \mathrm{min}^{-1}\right)$ željeni produkt veće čistoće pojavljuje se nakon $2 \mathrm{~h}$ sinteze ili nakon ispiranja uzorka, dok pri najvećoj brzini mljevenja (750 o $\mathrm{min}^{-1}$ ), neovisno o polaznom reaktantu produkt nastaje već nakon $1 \mathrm{~h}$ sinteze. Produkt najveće čistoće, čak i pri najmanjoj brzini mljevenja, dobiven je s polaznim reaktantom kalcijeva klorida, dok je najveće zaostajanje polaznog reaktanta uočeno u sintezi s kalcijevim nitratom. Nadalje, rezultate FTIR-a slijede i rezultati termogravimetrijske analize koji potvrđuju jednu, najstabilniju hidratnu fazu kalcijeva oksalata u svim uzorcima. Analiza mikroskopskih snimki nije dala informaciju o morfologiji kristala, dok raspodjela veličina čestica upućuje na nastajanje sustava s vidljive dvije populacije. U svim primjerima uočeno je da se povećanjem brzine mljevenja smanjuje veličina čestica. Pojava se može objasniti činjenicom da uspostavljanjem visokoenergetskog stanja sustava uslijed rotacija i vibracija komponenti mlina, dolazi do udaranja kuglica visokih energija ovisnih o brzini mljevenja kojim se pospješuju mehanokemijski procesi usitnjavanja.

\section{Popis kratica i simbola}

\section{List of abbreviations and symbols}

$$
\begin{aligned}
& \text { COM - kalcijev oksalat monohidrat } \\
& \text { - calcium oxalate monohydrate } \\
& \text { COD - kalcijev oksalat dihidrat } \\
& \text { - calcium oxalate dihydrate } \\
& \text { COT - kalcijev oksalat trihidrat } \\
& \text { - calcium oxalate trihydrate } \\
& \text { DLS - dinamičko raspršenje svjetlosti } \\
& \text { - dynamic light scattering } \\
& t_{\mathrm{e}} \quad \text { - temperatura kraja razgradnje, }{ }^{\circ} \mathrm{C} \\
& \text { - end of degradation temperature, }{ }^{\circ} \mathrm{C} \\
& t_{0} \quad \text { - početna temperatura razgradnje, }{ }^{\circ} \mathrm{C} \\
& \text { - initial degradation temperature, }{ }^{\circ} \mathrm{C} \\
& t_{\max } \quad \text { - temperatura pri maksimalnoj brzini razgradnje, }{ }^{\circ} \mathrm{C} \\
& \text { - temperature of maximum degradation rate, }{ }^{\circ} \mathrm{C} \\
& \Delta m \quad \text { - gubitak mase uzorka, } g \\
& \text { - mass loss of sample, } g
\end{aligned}
$$

\section{Literatura \\ References}

1. K. P. Aggarwal, S. Narula, M. Kakkar, C. Tandonm, Nephrolithiasis, Molecular Mechanism of Renal Stone Formation and the Critical Role Played by Modulators, Biomed. Res. Int. 2013 (2013) 1-21, doi: https://doi.org/10.1155/2013/292953.

2. A. S. Bramley, M. J. Hounslow, R. L. Ryall, Aggregation during Precipitation from Solution. Kinetics for Calcium Oxalate Monohydrate, Chem. Engng. Sci. 52 (1997) 747-757, doi: https://doi.org/10.1016/S0009-2509(96)00447-2.

3. Lj. Brečević, D. Kralj, The influence of some amino acids on calcium oxalate dihydrate transformation, J. Cryst. Growth $\mathbf{7 9}$ (1986) 178-184, doi: https://doi.org/10.1016/0022-0248(86)90433-1.

4. Lj. Brečević, D. Kralj, J. Garside, Factors influencing the distribution of hydrates in calcium oxalate precipitation, J. Cryst. Growth 97 (1989) 460-468,

doi: https://doi.org/10.1016/0022-0248(89)90227-3.

5. P. Brown, D. Ackermann, B. Finlayson, Calcium oxalate dihydrate (weddellite) precipitation, J. Cryst. Growth 98 (1989) 285-292, doi: https://doi.org/10.1016/00220248(89)90143-7.

6. D. Škrtić, M. Marković, Lj. Komunjer, H. Füredi-Milhofer, Precipitation of calcium oxalates from high ionic strength solutions: I. Kinetics of spontaneous precipitation of calcium oxalate trihydrate, J. Cryst. Growth 66 (1984) 431-440, doi: https://doi.org/10.1016/0022-0248(84)90227-6.

7. D. Škrtić, H. Füredi-Milhofer, M. Marković, Precipitation of calcium oxalates from high ionic strength solutions: $\mathrm{V}$. The influence of precipitation conditions and some additives on the nucleating phase, J. Cryst. Growth 80 (1987) 113-120, doi: https://doi.org/10.1016/0022-0248(87)90530-6.

8. B. B. Tomažić, G. H. Nancollas, The dissolution of calcium oxalate kidney stones. A kinetic study. J. Urol. 128 (1982) 205-208,

doi: https://doi.org/10.1016/S0022-5347(17)52819-0. 
9. A. Šter, S. Šafranko, K. Bilić, B. Marković, D. Kralj, The effect of hydrodynamic and thermodynamic factors and the addition of citric acid on the precipitation of calcium oxalate dehydrate, Urolithiasis (2017) on line, doi: https://doi.org/10.1007/s00240-017-0991-0.

10. X.-Y. Sun, J.-M. Ouyang, M. Xu, Synthesis, characterization, and cytotoxicity assay of calcium oxalate dihydrate crystals in various shapes, CrystEngComm 18 (2016) 5463-5473, doi: https://doi.org/10.1039/C6CE00697C.

11. B. Grohe, S. Hug, A. Langdon, J. Jalkanen, K. A. Rogers, H. A. Goldberg, M. Karttunen, G. K. Hunter, Mimicking the biomolecular control of calcium oxalate monohydrate crystal growth: effect of contiguous glutamic acids, Langmuir 28 (2012) 12182-12190, doi: https://doi.org/10.1021/la3018985.

12. W. L. Suchaneka, P. Shuka, K. Byrappaa, R. E. Rimana, K. S. TenHuisenb, V. F. Janasb, Mechanochemical-hydrothermal synthesis of carbonated apatite powders at room temperature, Biomaterials 23 (2002) 699-710, doi: https://doi.org/10.1021/la3018985.

13. T. Tsuzuki, K. Pethick, P. G. McCormick, Synthesis of $\mathrm{CaCO}_{3}$ Nanoparticles by Mechanochemical Processing, J. Nanopart. Res. 2 (2000) 375-380, doi: https://doi.org/10.1023/A:101005150.

14. J. Kaloustian, T. F. El-Moselhy, H. Portugal, Determination of calcium oxalate (mono- and dihydrate) in mixtures with magnesium ammonium phosphate or uric acid: the use of simultaneous thermal analysis in urinary calculi, Clin. Chim. Acta 334 (2003) 117-129, doi: https://doi.org/10.1016/S0009-8981(03)00228-6.

15. T. Echigo, M. Kimata, A. Kyono, M. Shmizu, T. Hatta, Reinvestigation of the crystal structure of whewellite $\left[\mathrm{Ca}\left(\mathrm{C}_{2} \mathrm{O}_{4}\right) \cdot \mathrm{H}_{2} \mathrm{O}\right]$ and the dehydration mechanism of caoxite $\left[\mathrm{Ca}\left(\mathrm{C}_{2} \mathrm{O}_{4}\right) \cdot 3 \mathrm{H}_{2} \mathrm{O}\right]$, Mineral. Mag. 69 (2005) 77-88, doi: https://doi.org/10.1180/0026461056910235.

16. M. Berenyi, G. Liptay, The use of thermal analysis in medical science with special reference to nephroliths, J. Thermal. Anal. 3 (1971) 437-443, doi: https://doi.org/10.1007/BF02188652.

17. F. Grases, A. Millan, A. Conte, Production of calcium oxalate monohydrate, dihydrate or trihydrate, Urol. Res. 18 (1990) 17-20, doi: https://doi.org/10.1007/BF00294575.

18. W. O. S. Doherty, O. L. Crees, E. Senogles, The preparation of calcium oxalate dihydrate crystals, Cryst. Res. Technol. 29 (1994) 517-524, doi: https://doi.org/10.1002/crat.2170290412.

19. A. Periasamy, S. Muruganand, M. Palaniswamy, Vibrationl studies of $\mathrm{Na}_{2} \mathrm{SO}_{4}, \mathrm{~K}_{2} \mathrm{SO}_{4}, \mathrm{NaHSO}_{4}$ and $\mathrm{KHSO}_{4}$ crystals, J. Chem. 2 (2009) 981-989, ISSN: 0974-1496.

20. R. Frost, K. Erickson, T. Kloprogge, Vibrational spectroscopic study of the nitrate containing hydrotalcite Mbobomkulite, Spectrochimica Acta Part A 61 (2005) 2919-2925, doi: https://doi.org/10.1016/j.saa.2004.11.002.

\title{
SUMMARY
}

\author{
Mechanochemical Synthesis of Calcium Oxalate \\ Silvija Šafranko, ${ }^{a}$ Dominik Goman, ${ }^{a}$ Filip Bolić, ${ }^{a}$ Marina Sekulić, ${ }^{a}$ Anamarija Stanković, ${ }^{*}$ \\ Nives Matijaković, Ina Erceg, and Berislav Markovića
}

In this work, mechanochemical synthesis of calcium oxalate was done in a planetary ball mill, with and without addition of water as a solvent. Previous research was primarily focused on calcium oxalate synthesis in solution. Here we report a different approach which may contribute to new findings in calcium oxalate crystal synthesis caused by an influence of mechanical energy.

The aim of this study was synthesis, identification, and characterization of particular oxalate hydrate phase synthesized with calcium salts (chloride, nitrate and sulphate). The effects of milling speed and reaction duration regarding the time of synthesis were investigated. Structural and thermal sample properties were studied by FTIR spectroscopy and thermogravimetric analysis (TGA). Morphologic characteristics of calcium oxalate and size distribution were measured by optical microscopy and dynamic light scattering (DLS).

\section{Keywords}

Mechanochemistry, calcium oxalate monohydrate, kidney stones

a Department of Chemistry, University of Osijek, Ulica cara Hadrijana 8A, 31000 Osijek, Croatia

${ }^{b}$ Ruđer Bošković Institute, Laboratory for precipitation Accepted May 21, 2018 processes, Bijenička cesta 54, 10000 Zagreb, Croatia

c Ruđer Bošković Institute, Laboratory for biocolloids and surface chemistry, Bijenička cesta 54, 10000 Zagreb, Croatia 
